\title{
28. Looking to 2012: Lessons from 2007 and Arising Issues
}

\author{
Ray Anere and Katherine Wheen
}

The consensus that emerges from this volume is that the conduct of the 2007 Papua New Guinea general election was an improvement on the previous general election in 2002.

The prioritization of security, especially in the Highlands Region (chapters 6, 7 and 8), the improved whole-of-government coordination through the Interdepartmental Electoral Committee (chapters 2 and 5), and the increased recognition of the role of community engagement through electoral awareness (chapter 4) and domestic observation (chapter 5), are three stand-out improvements in 2007.

Each of these improvements clearly demonstrates that elections are multistakeholder events and not purely administrative exercises coordinated by the Papua New Guinea Electoral Commission (PNGEC). This recognition that electoral events require partnerships between multiple government agencies, political parties, non-government groups, churches, aspiring candidates, sitting members of parliament (MPs) and the various security forces reflects a growing maturity in the approach to elections in Papua New Guinea.

However, as chapter 5 on electoral administration explains, to be a success this thinking must be translated into much improved administration, planning, logistics and implementation. The many problems that are highlighted throughout this volume - late arrival of materials, late or inadequate training of electoral officers, partisan appointment of electoral officials, delayed release of funds, inadequate planning of polling day logistics, poor communications and transportation, and late implementation of electoral reforms (especially in relation to the creation of a new electoral roll and new ballot paper) - cut across the many agencies involved, but are felt most acutely within the PNGEC, an agency that struggles in terms of both capacity and funding.

It is not the intention of this chapter to make specific recommendations on how to improve the elections in 2012. These can be found elsewhere (Haley and Anere 2009; Anere and Wheen 2009; Nonggorr, Sepoe and Raga 2010; and Ladley, Holtved and Kantha 2010a, 2010b). Rather, this chapter acts as a summary of the issues and themes that emerged around the 2007 election and as an update on issues that are emerging as the current political cycle unfolds. 


\section{Political reform}

Chapter 3 notes that the 2007 elections followed a period of significant political reform in Papua New Guinea, the two largest reforms being the introduction of limited preferential voting (LPV) and the Organic Law on the Integrity of Political Parties and Candidates (OLIPPAC, popularly known as the integrity law).

The political will that underpinned both reforms was a very admirable desire to improve governance and political stability. But changing laws does not necessarily change behaviour. Reform at a political level if it is intended to solve complex cultural problems at a community or administrative level will always be of limited success and scope - as has been the case with LPV and OLIPPAC.

Though structural reforms have their place, the message of many authors in this volume is that emphasis must be on administrative preparedness and community engagement in elections. Both are more likely to yield longer-term gains than the perceived silver bullet of structural reform.

\section{Introduction of limited preferential voting}

LPV has proved a popular system, with members of the community frequently expressing to election observers the perception that LPV had contributed to safer and better elections (although this is impossible to measure when you consider the increased investment in election security in 2007).

The real impacts of LPV will take a long time to unfold. Certainly, it is increasing the 'mandate' of elected officials, who are winning office with a greater proportion of votes after preferences are distributed. Whether this greater 'representativeness' makes elected members more accountable to their voters remains to be seen.

What is immediately clear is that the LPV system is much more complex and this has many associated costs. It requires major ongoing investments in electoral education. Overall, there is very limited knowledge by voters and candidates of how preferences work, aside from a basic understanding of the need to make three choices instead of one.

Preference sharing agreements and/or strategies by candidates were not common, though present in a few electorates, often based on the imperative to 'use preferences to vote for locals not outsiders'. There is even less knowledge of how preferences are treated in the counting process. 
Counting procedures themselves have become much more complex, lasting a number of weeks in larger provincial electorates, contributing to post-election tensions. The fact that at the time of writing (May 2011) it was still not possible to analyze full election results from 2007, suggests that much needs to be done to improve the conduct and transparency of the scrutiny process.

The new voting system, combined with the introduction of a new ballot paper (which required voters to write down a candidate name or candidate number for each preference), appears to have also contributed to even higher levels of assisted voting.

The real and/or perceived status of LPV as a 'fairer system' may indeed influence political culture in Papua New Guinea to become more accommodative over time, but it has increased, and will continue to increase, the costs of planning, counting, training and awareness. This must be factored into all future elections.

\section{The integrity law, political parties and candidates}

The new integrity law, the OLIPPAC, contained a range of measures that were intended to improve political stability. As chapter 9 describes, these measures did not totally prevent party hopping (in part due to the poor understanding and selective implementation of the new legislation by the speaker of parliament), and appear to have had no effect on post-election horse trading to form government. However, the OLIPPAC certainly improved the stability of government-leading to the Somare government lasting a full parliamentary term from 2002 to 2007 and remaining in office from 2007 to date, and creating more stability in ministerial appointments in the period up to July 2010.

However, from the moment the OLIPPAC was passed into law, a number of measures looked certain to be challenged in the courts. The most controversial were those that regulated the parliamentary behaviour of MPs, forcing them to remain a member of and vote in accordance with their respective political parties for the duration of their term. In July 2010 these sections of the OLIPPAC were ruled unconstitutional. The Supreme Court, headed by Chief Justice Salamo Injia ruled that the restrictions placed on MPs were 'unheard of in any democratic country' and were 'not reasonably justifiable for the purpose for which they [had] been enacted' (Post-Courier 8 July 2010). This decision led almost immediately to a return to political party instability including shifting party alliances and party membership, ministerial reshuffles and prolonged adjournments of parliament to avoid votes-of-no-confidence. 
Political parties in Papua New Guinea remain entities that are constituted solely for the purpose of gaining election and forming governing coalitions. They remain unstable, unrepresentative, and in many instances poorly governed (exemplified by the number of parties failing to submit financial returns - see chapter 3), despite regulations within the OLIPPAC aimed at improving party governance and transparency.

There remains only one dominant party, the National Alliance, which has been successful in selecting popular candidates to contest elections and appealing to independents, once elected. This is due in some part to the continued leadership of Sir Michael Somare. However, as this political cycle unfolds, the National Alliance will struggle to contain the competing personalities within, especially as the retirement of the prime minister appears likely (though by no means certain) in this term and potential successors position themselves accordingly.

Somare has lately been suspended from office for two weeks, after being found guilty of 13 counts of misconduct in office relating to his failure to lodge financial returns, as required under the Leadership Code, over a period of 20 years (PostCourier 25 March 2011).

Large numbers of candidates contesting elections continued in 2007 with 2759 candidates contesting. These large numbers of candidates - a feature of the political culture in the Highlands and in other parts of the country-will be difficult to restrict without facing some of the same challenges as the OLIPPAC. Both issues sit on the fine line between political stability and political freedom.

\section{New provinces and changes to electoral boundaries}

One impact of the lengthy adjournments of parliament that have occurred during recent parliamentary sessions has been delayed decisions on legislation. This is certain to make a big impact on election administration and planning in the lead-up to 2012. The complex pieces of legislation, requiring multiple readings and large majorities, include the introduction of the two new provinces Hela (now part of Southern Highlands Province) and Jiwaka (now part of Western Highlands Province); the clarification of electoral boundaries and the status of provincial electorates in general; and the proposed introduction of 22 reserved seats for women.

Delays in passing legislation, and poor implementation of decisions in relation to either of these two issues - but most especially the two new provinces - have the potential to cause increased volatility in 2012 in problem areas such as the 
Southern Highlands. The proposed new, oil-rich Hela Province is the home of major new liquefied natural gas developments and is for this and other cultural reasons considered a hotspot for election-related violence if the introduction of the new province is not managed smoothly (McPherson 2009). For more information on the special challenges of the Southern Highlands region see chapters $6,19,20$ and 21 .

The 2002-2007 political cycle also left some uncertainty as to the status of provincial electorates. Previously, under the Morauta government and in the early period of the Somare government, there had been a consensus (albeit temporary) to abolish provincial electorates. This was only partially achieved in terms of the required legislative changes, before the Somare government then decided to retain provincial electorates. Ensuring all the relevant legislation is now consistent with this position, and ensuring that the constitutionally required number of open electorates (currently 110-120) is consistent with the actual number (89) is an urgent task for the current government.

Although it is unlikely to be implemented in this political cycle, the problem of open electorate boundaries will remain on the political horizon. Open electorates remain significantly unequal in terms of their relative population size, yet their boundaries are very difficult to change and remain as they were at independence. This impasse is due to the vested interests of the very people that, under the Constitution, must vote to change boundaries - the elected members themselves.

\section{Women's participation and representation}

One of the key assumptions of LPV was that it would increase the likelihood of women candidates being elected. This view was misplaced. While LPV can be seen to increase the proportion of votes that women receive after preferences are distributed, in all but one case, the low primary vote for female candidates saw them excluded early in count in 2007 before they had a chance to attract preference votes (see chapters 10, 15 and 25). Even the sole female MP elected, member for Moresby South, Dame Carol Kidu, received fewer preference votes than her nearest (male) rival.

The male-dominated political culture of Papua New Guinea, deriving from the male-dominated leadership culture of most communities, continues to make it extremely difficult for women to compete with men for political office.

To rectify this electoral imbalance after 2007, Dame Kidu initially championed the introduction of three nominated female MPs, using existing constitutional provisions. This measure failed to win the support of a great number of MPs 
including the opposition. The reasons were varied but there proved to be much discomfort with the notion of having unelected MPs. Instead, a working group proposed new legislative changes to create 22 reserved, elected seats for women - one for each province. Passing these changes through the maledominated parliament in itself will be a challenge, let alone implementing the changes around the country.

\section{Election security}

The mobilization of security, especially in the Highlands Region, was arguably the greatest success of 2007. Chapters 6, 7 and 8 record the experiences of security forces on the ground in Southern Highlands and Chimbu and describe in detail their achievements and challenges.

The pre-deployment of security two weeks before polling for reconnaissance was a particular success, as was the impressive discipline, on the whole, observed in each of the forces.

The notion of a rolling election through the Highlands Region, in order to concentrate on different highland provinces separately, also allowed greater numbers of security personnel on the ground. But as with most election logistics, this could have been much better planned and implemented. One-day polling, however, proved impossible from a security perspective.

2007 also saw the security forces becoming involved in administering polling, and not simply maintaining the security of polling and counting areas (see chapter 8 ). Despite the fact that many security officials willingly took on this role and stepped in where electoral officials were failing, the security officials had limited knowledge of election processes. The lesson for the future is to conduct election-specific training for, and increase the resources to, security forces in order to better perform this role. The simple fact is that security forces tend to be better disciplined, better educated, have better communications, and appear to be more impartial than many electoral officials hired in local areas.

There is a major emerging threat to security mobilization in the lead-up to 2012. The rise of the private security industry, both in the nation's capital Port Moresby, but more recently to secure massive new resource projects including liquefied natural gas project infrastructure across the country, has seen the widespread recruitment of underpaid and under-resourced police and defence force personnel. These developments have the potential to absorb much of the security capacity that needs to be deployed during the 2012 elections. 
Resource development companies across the country will also have to become election stakeholders and make a contribution to election safety and security, if they want to see their current and future investments protected from the disruption of elections. How these companies might take to this proactive partnership role remains to be seen.

\section{Inter-departmental Electoral Committee}

The success of the security operations can also be attributed to the wholeof-government-approach coordinated by the Inter-departmental Electoral Committee. There is a strong sense that the whole-of-government approach encouraged cooperation, collaboration, coordination, accountability and sharing of information between the security forces, electoral commission, and other departments.

Keeping up the momentum and enthusiasm to participate in the Interdepartmental Electoral Committee by all relevant agencies will be the challenge for 2012 .

\section{The electoral roll}

The creation of a new electoral roll for 2007, although an improvement on the 2002 roll, was not a success. Although the re-enrolment exercise reduced the number of names on the roll, it is clear that especially in the Highlands Region the roll 'does not provide a credible link between eligible electors and the votes counted during an election' (Ladley, Holtved and Kantha 2010a, quoted in chapter 5).

Chapters 5 overviews the major flaws in both the re-registration and verification exercises in 2006-2007 and most of the electorate-specific chapters in the second half of the book detail roll-related problems around the country, especially chapter 21 on the Koroba-Lake Kopiago Open electorate. The late commencement of the exercise was one handicap; partisan officials, poor planning, and a cultural disrespect for the roll all played their part.

As Ladley, Holtved and Kantha (2010a) have outlined in their post-election analysis of the problems with the electoral roll that 'there are no quick fixes for improving the electoral roll and voter identification in Papua New Guinea'. The employment of technological options, including photo identification and/or fingerprint systems, which had been canvassed after 2007, will only work once much groundwork is done. 
Instead, good management systems at the national, provincial and ward level; enrolment, verification and updating procedures that can be depended on; and, significantly, the support of the people when registering to vote and on polling day, are all needed first. This requires a holistic approach to improving the electoral roll and much improved capacity and funding for the PNGEC (Ladley, Holtved and Kantha 2010a).

To its credit, the PNGEC has placed much greater emphasis in 2010 on building the capacity of provincial election managers in relation to management and verification of the roll, and has piloted initiatives aimed at structuring the roll to better match clan systems within communities.

However, this activity is not yet on the scale that is required for wholesale improvements to roll-related systems. What does happen between now and the election in 2012 will again occur late in the electoral cycle.

What is certain, as Haley writes in chapter 5, is that 'attention must be given to the electoral roll as a matter of urgency, in order to ensure political equality between citizens, restore confidence in the PNGEC, and ensure that the elections have integrity'.

\section{Community engagement in elections}

Community engagement and awareness is emerging as an important part of elections in Papua New Guinea. Community engagement can be understood as everything from delivering electoral education on how to vote correctly, through conducting activities to build demand in communities for fairer elections and good governance, to encouraging community participation in elections through activities like domestic observation.

As chapters 4 and 5 outlined, these activities were first implemented on a national scale in the lead-up to 2007, and significantly supported by the Australian Agency for International Development-funded Electoral Support Program Phase 2.

As with any new initiative, the community engagement programs faced a range of teething problems, particularly with encouraging traditional election actors, especially within the commission, to see non-government groups as complementary partners, rather than competitors for resources. Indeed in many respects the best community engagement towards encouraging fairer elections was done by non-government actors, who are themselves much closer to communities (see chapter 11). 
This aspect of election planning relied heavily on donor support and donor coordination. In the lead-up to 2012, it will be important to enhance this aspect of elections. It will also be important for the PNGEC to take more ownership over coordinating these important partnerships and acting in closer contact with communities.

\section{Electoral administration}

Finally, what has infused much of the discussion above is the overall significance of good election administration and planning on the conduct of successful elections.

The list of areas where administration could be improved is long and includes better coordination of human resources including training, production and distribution of polling materials, communication and transportation arrangements, and timely release of funds, to name just a few.

The PNGEC and the chief electoral commissioner have the unenviable job of managing an organization that must transform from some 60 staff in normal operating periods to a nationwide organization that engages, organizes and directs thousands of officials around the country during elections.

The increased allocation of financial resources to the PNGEC in last year's budget, announced in November 2010, reflected a growing realization that the PNGEC needs to be resourced throughout an electoral cycle to make the needed improvements and conduct the necessary strategic planning to administer elections. More funding is beginning to be secured. Now it is strategies for improving the human and institutional capacity of the commission and its people around the country (but most especially in the Highlands) where the greatest emphasis should be placed in electoral reform in the lead-up to 2012 and beyond.

\section{References}

Anere, R. and Wheen, K., 2009. Priorities for a Free and Fair Election: An NRI Issues Analysis. Discussion Paper No. 107. Port Moresby: The National Research Institute.

Haley, N. and Anere, R., 2009. The 2007 Papua New Guinea National General Elections: Domestic Observation Report. Special Publication No. 52. Port Moresby: The National Research Institute. 
Ladley, A., Holtved, O. and Kantha, S., 2010a. Improving the Electoral Roll and Voter Identification in Papua New Guinea. Discussion Paper No. 111. Port Moresby: The National Research Institute.

Ladley, A., Holtved, O. and Kantha, S., 2010b. Realigning Electoral Incentives: Lessons for the 2012 National General Election from Conflict Theory and Public Policy. Discussion Paper No. 112. Port Moresby: The National Research Institute.

McPherson, J., 2009. Electorates for the Next Parliament and Related Matters. Discussion Paper No. 98. Port Moresby: Institute for National Affairs.

Nonggorr, J., Sepoe, O. and Raga, B., 2010. Review of the Legal Framework for Managing Elections in PNG. Report submitted to the Papua New Guinea Electoral Commission 19 March 2010. 